\title{
Sodium Selenite Enhances Antibiotics Sensitivity of Pseudomonas aeruginosa and Deceases Its Pathogenicity by Inducing Oxidative Stress and Inhibiting Quorum Sensing System
}

\author{
Weina Kong ${ }^{1,+}$, Qianqian Tian ${ }^{1,+}$, Qiaoli Yang ${ }^{1}$, Yu Liu ${ }^{1}$, Gongting Wang ${ }^{1}$, Yanjun Cao ${ }^{1}$, Liping Wang ${ }^{1}$, \\ Sizhe Xia ${ }^{1}$, Yanmei Sun ${ }^{1}$, Cheng Zhao ${ }^{1}$ and Shiwei Wang ${ }^{1,2, * \mathbb{D}}$
}

Citation: Kong, W.; Tian, Q.; Yang, Q.; Liu, Y.; Wang, G.; Cao, Y.; Wang, L.; Xia, S.; Sun, Y.; Zhao, C.; et al. Sodium Selenite Enhances Antibiotics Sensitivity of Pseudomonas aeruginosa and Deceases Its Pathogenicity by Inducing Oxidative Stress and Inhibiting Quorum Sensing System. Antioxidants 2021, 10, 1873. https:// doi.org/10.3390/antiox10121873

Academic Editor: Nikolai V. Gorbunov

Received: 25 October 2021

Accepted: 19 November 2021

Published: 24 November 2021

Publisher's Note: MDPI stays neutral with regard to jurisdictional claims in published maps and institutional affiliations.

Copyright: (C) 2021 by the authors. Licensee MDPI, Basel, Switzerland. This article is an open access article distributed under the terms and conditions of the Creative Commons Attribution (CC BY) license (https:// creativecommons.org/licenses/by/ $4.0 /$ )
1 Key Laboratory of Resources Biology and Biotechnology in Western China, Ministry of Education, The College of Life Sciences, Northwest University, Xi'an 710069, China; kongwn@nwu.edu.cn (W.K.); tianqianqian@stumail.nwu.edu.cn (Q.T.); yangqiaoli@stumail.nwu.edu.cn (Q.Y.);

liuyu1@stumail.nwu.edu.cn (Y.L.); wanggongting@stumail.nwu.edu.cn (G.W.); cao2014@nwu.edu.cn (Y.C.); wangliping@stumail.nwu.edu.cn (L.W.); xiasizhe@stumail.nwu.edu.cn (S.X.); sunyanmei@nwu.edu.cn (Y.S.); zhaocheng@stumail.nwu.edu.cn (C.Z.)

2 Provincial Key Laboratory of Biotechnology of Shaanxi Province, College of Life Sciences, Northwest University, Xi'an 710069, China

* Correspondence: wangsw@nwu.edu.cn

$\dagger$ These authors contributed equally to this work.

Abstract: Pseudomonas aeruginosa, a Gram-negative opportunistic pathogen, is commonly found in clinical settings and immuno-compromised patients. It is difficult to be eradicated due to its strong antibiotic resistance, and novel inactivation strategies have yet to be developed. Selenium is an essential microelement for humans and has been widely used in dietary supplement and chemoprevention therapy. In this study, the physiological and biochemical effects of sodium selenite on $P$. aeruginosa PAO1 were investigated. The results showed that $0 \sim 5 \mathrm{mM}$ sodium selenite did not impact the growth of PAO1, but increased the lethality rate of PAO1 with antibiotics or $\mathrm{H}_{2} \mathrm{O}_{2}$ treatment and the antibiotics susceptibility both in planktonic and biofilm states. In addition, sodium selenite significantly reduced the expression of quorum sensing genes and inhibited various virulence factors of this bacterium, including pyocyanin production, bacterial motilities, and the type III secretion system. Further investigation found that the content of ROS in cells was significantly increased and the expression levels of most genes involved in oxidative stress were up-regulated, which indicated that sodium selenite induced oxidative stress. The RNA-seq result confirmed the phenotypes of virulence attenuation and the expression of quorum sensing and antioxidant-related genes. The assays of Chinese cabbage and Drosophila melanogaster infection models showed that the combination of sodium selenite and antibiotics significantly alleviated the infection of PAO1. In summary, the results revealed that sodium selenite induced oxidative stress and inhibited the quorum sensing system of $P$. aeruginosa, which in turn enhanced the antibiotic susceptibility and decreased the pathogenicity of this bacterium. These findings suggest that sodium selenite may be used as an effective strategy for adjunct treatment of the infections caused by P. aeruginosa.

Keywords: Pseudomonas aeruginosa; sodium selenite; antibiotic susceptibility; quorum sensing; ROS; oxidative stress

\section{Introduction}

Pseudomonas aeruginosa is a ubiquitous Gram-negative opportunistic bacterium that can cause respiratory and urinary tract, burn, and wound infections [1,2]. It harbors a broad arsenal of virulence factors for infections establishment, including pyoverdine, pyocyanin, rhamnolipids, hemolysins, and proteases, and they largely contribute to bacterial 
pathogenesis [3]. In addition, biofilm is an important factor that causes bacterial antibiotic resistance. The widespread use of antibiotics leads to the increasing emergence and spread of multidrug-resistant strains (MDR), making the traditional antibiotic therapy against P. aeruginosa infection ineffective [4]. Thus, it is urgent to develop novel antibacterial agents for effectively treating MDR infections, such as phage therapy, nanoparticle therapy, and quorum sensing inhibitors [5].

Quorum sensing has been believed to be an excellent antibacterial drug target. It is involved in a process of cell-to-cell chemical communication and relies on bacterial production, detection, and response to extracellular signaling molecules called autoinducers [6]. Many ordinated behaviors of bacteria are regulated by the quorum sensing system, such as bioluminescence [7], virulence factor production [8], secondary metabolite production [9], and biofilm formation [10]. Three quorum sensing systems have been found in P. aeruginosa, including las, $r h l$, and pqs. In the las and $r h l$ systems, the signaling molecules are acyl-homoserine lactones, and for $p q s$ it is 2-heptyl-3-hydroxy-4-quinolone. These quorum sensing systems coordinate the regulation of virulence factors and biofilm formation of $P$. aeruginosa, and it is thought that the breakdown of quorum sensing systems may lead to a significant reduction in bacterial pathogenicity [11]. Thus, the inhibition of quorum sensing systems can be a novel and effective way to fight this MDR bacterium.

Selenium is one of the trace elements necessary for human bodies and many organisms, and it was discovered by Swedish chemist Jons Jacob Berzelius in 1817. Initially, selenium was considered to be toxic, while until the 1950s selenium was found to be a basic element of organisms [12]. Selenium has important biological functions and affects organisms in a dose-dependent manner. In the environment, it exists in many forms, such as selenate $\left(\mathrm{Se}^{+6}\right)$, selenite $\left(\mathrm{Se}^{+4}\right)$, elemental selenium $\left(\mathrm{Se}^{0}\right)$, selenide $\left(\mathrm{Se}^{-2}\right)$, selenocysteine, selenomethionine, etc. $[13,14]$. Selenium compounds can react with a thiol to form highly reactive and unstable metabolites, and these metabolites then react with oxygen and generate reactive oxygen species (ROS) [15], which can cause cell damage, such as protein and lipid peroxidation and DNA oxidation [16]. Among these selenium compounds, sodium selenite has long been regarded as one with the most redox activity to produce ROS and the most effective to kill cancer cells $[17,18]$, and it has a strong ability to oxidize mercaptan substances, such as glutathione (GSH) and thioredoxin (Trx).

Although selenium has been well known as an antioxidant and anticancer agent [19] and also has been reported to have strong antibacterial activity against some planktonic cells of bacteria, such as Bacillus subtilis, Staphylococcus aureus, Escherichia coli, and Klebsiella planticola [20], the detailed effects of selenite on bacterial physiology remain to be explored. In this study, the low concentration of selenite $(0.5 \sim 5 \mathrm{mM})$ was found to have no effects on $P$. aeruginosa growth, but obviously increased the lethality rate of this bacterium with antibiotics or $\mathrm{H}_{2} \mathrm{O}_{2}$ treatment. The antibiotic susceptibility in planktonic and biofilm states was both increased, and the bacterial virulence and pathogenicity were reduced. The detailed mechanisms were further investigated by bioinformatics and biochemical methods.

\section{Materials and Methods}

\subsection{Bacterial Strains and Culture Conditions}

The bacterial strains and plasmids used in this study are listed in Table 1. The P. aeruginosa strains were routinely cultivated at $37^{\circ} \mathrm{C}$ in LB medium without sodium chloride (LBNS, peptone $10.0 \mathrm{~g} / \mathrm{L}$, yeast extract $5.0 \mathrm{~g} / \mathrm{L}, \mathrm{pH}$ 7.0). When necessary, antibiotics were used at the following concentrations: for E. coli, kanamycin $(\mathrm{Kn})$ at $50 \mu \mathrm{g} / \mathrm{mL}$; for P. aeruginosa, trimethoprim (Tmp) at $500 \mu \mathrm{g} / \mathrm{mL}$. For growth curve detection, P. aeruginosa PAO1 was cultured in $5 \mathrm{~mL}$ LBNS broth at $37^{\circ} \mathrm{C}$ and $200 \mathrm{rpm}$ overnight, and $50 \mu \mathrm{L}$ of culture was transferred into $5 \mathrm{~mL}$ of fresh LBNS broth with $0,0.5,1,5,10$, and $20 \mathrm{mM}$ sodium selenite and incubated at $37^{\circ} \mathrm{C}$ for $12 \mathrm{~h}$. The absorbance value at $600 \mathrm{~nm}\left(\mathrm{OD}_{600}\right)$ of the culture was measured by ultraviolet spectrophotometry. The medium for swarming motility examination consisted of $0.8 \%$ nutrient broth (Oxoid, Basingstoke, UK), $0.5 \%$ D-glucose, and $0.5 \%$ agar [21]. The swimming motility medium was comprised of $0.8 \%$ 
nutrient broth, $0.5 \%$ D-glucose, and $0.3 \%$ agar. Thin LBNS plates with $1 \%$ agar were used for twitching motility assay.

Table 1. Bacterial strains, plasmids, and primers used in this study.

\begin{tabular}{|c|c|c|c|}
\hline Names $^{1}$ & Relevant Characteristics & $\begin{array}{l}\text { Accession Number of } \\
\text { the Involved Genes }{ }^{2}\end{array}$ & Source \\
\hline \multicolumn{4}{|l|}{ Strains } \\
\hline E. coli DH5 $\alpha$ & $\begin{array}{c}F^{-} \text {p80lacZ } \Delta M 15 \Delta(\text { lacZYA-argF }) U 169 \text { recA1 endA1 hsdR17 } \\
\left(r k, m k^{+}\right) \text {phoA supE44 thi-1 gyrA96 relA1 tonA }\end{array}$ & - & Tiangen \\
\hline P. aeruginosa PAO1 & P. aeruginosa wild type & - & this lab \\
\hline PAO1 (pHERD20T-pqsR-gfp) & PAO1 containing pqsR-gfp reporter plasmid pHERD20T $\left(\mathrm{Cb}^{\mathrm{r}}\right)$ & 879994 & this lab \\
\hline PAO1 (pHERD20T-lasR-gfp) & PAO1 containing lasR-gfp reporter plasmid pHERD20T $\left(\mathrm{Cb}^{\mathrm{r}}\right)$ & 881789 & this lab \\
\hline PAO1 (pHERD20T-rhlR-gfp) & PAO1 containing rhlR-gfp reporter plasmid pHERD20T $\left(\mathrm{Cb}^{\mathrm{r}}\right)$ & 878968 & this lab \\
\hline \multicolumn{4}{|l|}{ Plasmids } \\
\hline CTX-exos & $\begin{array}{l}\text { Integration plasmid, CTX6.1 with a fragment of pKD-exoS } \\
\text { containing exoS promoter region and luxCDABE gene; Kn } \\
\qquad \operatorname{Tmp}^{\mathrm{r}}, \mathrm{Tc}^{\mathrm{r}}\end{array}$ & 879837 & this lab \\
\hline CTX-ехот & $\begin{array}{c}\text { Integration plasmid, CTX6.1 with a fragment of pKD-exoT } \\
\text { containing exoT promoter region and luxCDABE gene; } \mathrm{Kn}^{\mathrm{r}} \\
\mathrm{Tmp}^{\mathrm{r}}, \mathrm{Tc}^{\mathrm{r}}\end{array}$ & 878350 & this lab \\
\hline pMS402 & $\begin{array}{l}\text { Expression reporter plasmid carrying the promoterless } \\
\text { lux } C D A B E \text { gene; } \mathrm{Kn}^{\mathrm{r}}, \mathrm{Tmp}^{\mathrm{r}}\end{array}$ & - & [21] \\
\hline pKD-sodM & pMS402 containing sodM promoter region; $\mathrm{Kn}^{\mathrm{r}}, \mathrm{Tm}^{\mathrm{r}}$ & 881040 & this study \\
\hline pKD-katB & pMS402 containing katB promoter region; $\mathrm{Kn}^{\mathrm{r}}, \mathrm{Tmp}^{\mathrm{r}}$ & 881120 & this study \\
\hline pKD-ahpC & pMS402 containing $a h p C$ promoter region; $\mathrm{Kn}^{\mathrm{r}}, \mathrm{Tmp}^{\mathrm{r}}$ & 879431 & this study \\
\hline $\mathrm{pKD}-g \operatorname{sh} B$ & pMS402 containing gshB promoter region; $\mathrm{Kn}^{\mathrm{r}}, \mathrm{Tmp}^{\mathrm{r}}$ & 878223 & this study \\
\hline Primers & Sequence $\left(5^{\prime} \rightarrow 3^{\prime}\right)$ & & Restriction sites \\
\hline sodM-S & TATCTCGAGTGGTCGAGTCGATGATGG & 881040 & Xho I \\
\hline sodM-A & ATAGGATCCGACATGGCAACCTCACCA & 881040 & Bam $\mathrm{HI}$ \\
\hline katB-S & GATCTCGAGTCACTCCCTGTATTTCGC & 881120 & Xho I \\
\hline katB-A & GTAGGATCCAGGGTTCATGGAAGAGCT & 881120 & Bam $\mathrm{HI}$ \\
\hline $\operatorname{ahpC-S}$ & GATCTCGAGGGCAGGTTCTTCGATTAG & 879431 & Xho I \\
\hline $\operatorname{ahpC-A}$ & GTTGGATCCTCAGGGACATCAGTCGTT & 879431 & Bam $\mathrm{HI}$ \\
\hline$g \operatorname{shB}-\mathrm{S}$ & GATCTCGAGCACTTTCAAACCGTCGGA & 878223 & Xho I \\
\hline$g \operatorname{sh} B-\mathrm{A}$ & GAAGGATCCCGTACGCTCATGGGAATT & 878223 & Bam $\mathrm{HI}$ \\
\hline
\end{tabular}

${ }^{1}$ E. coli DH5 $\alpha$ was purchased from Beijing Tiangen Biochemical Technology Co. Ltd., Beijing, China. P. aeruginosa wild-type strain PAO1, the wild-derived strains, pKD-sodM, pKD-katB, pKD-ahpC and pKD-gshB were stored in this laboratory (Key Laboratory of Resources Biology and Biotechnology in Western China, Ministry of Education, College of Life Sciences, Northwest University, Xi'an, China). ${ }^{2}$ ID of the involved genes was displayed; -, not applicable. The underlines indicated restriction enzyme sites.

\subsection{Survival Assays of Antimicrobial Treatment}

The survival of PAO1 with various antimicrobial challenges was assayed as described previously with minor modification [22]. In brief, after culture overnight, $200 \mu \mathrm{L}$ aliquots were transferred to $5 \mathrm{~mL}$ fresh LBNS medium with different antibiotics that have no significant effect on the growth of PAO1 (including $2 \mu \mathrm{g} / \mathrm{mL}$ gentamicin, $0.5 \mu \mathrm{g} / \mathrm{mL}$ tobramycin, $15 \mu \mathrm{g} / \mathrm{mL}$ ampicillin, $20 \mathrm{ng} / \mathrm{mL}$ ciprofloxacin, or $9 \mu \mathrm{g} / \mathrm{mL}$ tetracycline) and a final concentration of $5 \mathrm{mM}$ sodium selenite. As regards the $\mathrm{H}_{2} \mathrm{O}_{2}$ challenge, a final concentration of $3 \mathrm{mM} \mathrm{H}_{2} \mathrm{O}_{2}$ was used under the condition with or without $5 \mathrm{mM}$ sodium selenite. After $1 \mathrm{~h}, 2 \mathrm{~h}, 3 \mathrm{~h}$, or $4 \mathrm{~h}$ growth, the cultures were diluted serially and plated on LBNS agar plates at $37^{\circ} \mathrm{C}$ overnight. The colony-forming units (CFUs) were counted and the survival rates were calculated. 


\subsection{Determination of Minimal Inhibitory Concentration (MIC), Minimal Biofilm Inhibitory Concentration (MBIC), and Minimal Biofilm Eradication Concentration (MBEC) with the Combination of Sodium Selenite and Antibiotics}

MIC of antibiotics with or without sodium selenite was detected by the broth microdilution method as previously described [23]. Briefly, gentamicin and tobramycin ranging from 0.25 to $64 \mu \mathrm{g} / \mathrm{mL}$ were prepared using 2-fold serial dilutions in 96-well polyvinyl chloride plates (Corning/Costar, Corning, NY, USA) with $100 \mu \mathrm{L}$ of LBNS broth per well, respectively. Selenite was added into parallel wells to obtain 1- or 5-mM final concentrations, and no selenite samples were detected as controls. Then, $1 \mu \mathrm{L}$ of overnight cultures of $P$. aeruginosa PAO1 were added and the plates were incubated at $37^{\circ} \mathrm{C}$ for $12 \mathrm{~h}$. $\mathrm{OD}_{600}$ was measured. The lowest concentration of antibiotics with or without selenite that inhibited bacterial growth until $\mathrm{OD}_{600}<0.1$ after $12 \mathrm{~h}$ incubation was taken as MIC. The measurement of MBIC and MBEC was performed on 96-well plates as described above. MBIC represented the minimum concentration of antibiotics and selenite that lead to biofilm formation with $\mathrm{OD}_{560}<0.1$, and MBEC was the minimum concentration of antibiotics and selenite that eliminated the 10 -h biofilm $\left(\mathrm{OD}_{560}<0.1\right)$. MBIC was detected after static growth for $12 \mathrm{~h}$ at $30{ }^{\circ} \mathrm{C}$. MBEC was determined after $12 \mathrm{~h}$ of treatment to the formed biofilm by different concentrations of antibiotics and selenite.

\subsection{Biofilm Formation Measurement}

Biofilm formation was measured in a static system as previously described [24]. In brief, overnight cultures were diluted at 1:100 in a fresh LBNS medium, and $100 \mu \mathrm{L}$ of the medium was transferred into 96-well polyvinyl chloride plate. Sodium selenite was added until a final concentration of $5 \mathrm{mM}$. After incubation at $37^{\circ} \mathrm{C}$ for $5 \mathrm{~h}$ without shaking, the free-floating planktonic cells were removed and wells were washed three times with distilled water. Biofilms were stained with $120 \mu \mathrm{L}$ of $0.1 \%$ crystal violet for $20 \mathrm{~min}$, and each well was washed with water to remove unbound dye. The remaining crystal violet was dissolved in $200 \mu \mathrm{L}$ of $30 \%$ glacial acetic acid and $125 \mu \mathrm{L}$ of the solution was transferred to the 96-well microtiter plate. The absorbance at $560 \mathrm{~nm}\left(\mathrm{OD}_{560}\right)$ was measured.

\subsection{Pyocyanin Production Assay}

The assay of pyocyanin production was carried out according to the method described previously with slight modifications [25]. Briefly, overnight cultures were inoculated at 1:100 dilutions into $5 \mathrm{~mL}$ fresh LBNS broth with or without $5 \mathrm{mM}$ sodium selenite and incubated at $37^{\circ} \mathrm{C}$ for $48 \mathrm{~h}$. Pyocyanin was extracted from the culture supernatants by adding $3 \mathrm{~mL}$ of chloroform. After extraction, the chloroform layer was transferred into a new tube and mixed with $1 \mathrm{~mL}$ of $0.2 \mathrm{M} \mathrm{HCl}$. The top layer was removed after centrifugation and the absorbance was measured at $520 \mathrm{~nm}\left(\mathrm{OD}_{520}\right)$. Concentrations, expressed as $\mu \mathrm{g}$ of pyocyanin produced per $\mathrm{mL}$ of culture supernatant, were determined by multiplying $\mathrm{OD}_{520}$ by 17.072 [26].

\subsection{Bacterial Motility Examination}

For swarming and swimming examination, $2 \mu \mathrm{L}$ of overnight culture was inoculated onto plates at $37^{\circ} \mathrm{C}$ for $12 \mathrm{~h}$. Twitching motility was assayed by stab-inoculating bacteria through the thin LBNS agar plates at $30^{\circ} \mathrm{C}$ for $24 \mathrm{~h}$ under humidified conditions. Sodium selenite was used until a final concentration of $5 \mathrm{mM}$. Photographs were taken using a Tanon 2500 imaging system and the diameter of the movement circle was measured. Each experiment was repeated three times.

\subsection{Rhamnolipid Quantification}

Rhamnolipid was measured using the modified colorimetric anthrone assay [27]. In brief, bacteria were cultured for $48 \mathrm{~h}$ in nutrient broth with or without $5 \mathrm{mM}$ sodium selenite, and $2 \mathrm{~mL}$ of fermentation liquid were centrifuged to extract the supernatant. An aliquot of $400 \mu \mathrm{L}$ anthrone $\left(0.2 \%\right.$ anthrone in $\left.85 \% \mathrm{H}_{2} \mathrm{SO}_{4}\right)$ was added to $100 \mu \mathrm{L}$ supernatant 
and heated at $100{ }^{\circ} \mathrm{C}$ for $30 \mathrm{~min}$. The mixture was allowed to cool to room temperature and the absorbance at $620 \mathrm{~nm}\left(\mathrm{OD}_{620}\right)$ was measured. Rhamnolipid levels in the supernatant were calculated according to the standard curve, which was obtained with rhamnose standards (Solarbio, Beijing, China).

\subsection{Construction of the Promoter-Reporter Plasmids}

The plasmid pMS402 was used to construct gene expression vectors as reported previously [28]. The promoter regions of target genes were respectively amplified by PCR using the corresponding primers (Table 1). The PCR products were cloned into the BamHI-XhoI site upstream of the lux genes on pMS402. The constructed plasmids were transformed into E. coli DH5 $\alpha$ competent cells and the positive clones were screened out by $50 \mu \mathrm{g} / \mathrm{mL}$ kanamycin and DNA sequencing.

\subsection{Gene Expression Analysis}

Gene expression of $l u x$-based reporters in liquid cultures was measured as counts per second (cps) of light production in a Synergy H2 Plate Reader (Biotek, Winooski, VT, USA). Overnight cultures of the reporter strains were diluted at 1:20 and incubated for an additional $3 \mathrm{~h}$. The cultures were inoculated into parallel wells of a black 96-well plate with a transparent bottom. A volume of $10 \mu \mathrm{L}$ of the fresh cultures were inoculated into the wells containing $90 \mu \mathrm{L}$ of LBNS medium with or without $5 \mathrm{mM}$ sodium selenite. Forty microliters of filter-sterilized mineral oil was added to prevent evaporation during the assay. Bacterial growth and promoter activities were measured in the microplate reader every $2 \mathrm{~h}$ intervals for $24 \mathrm{~h}$.

\subsection{Measurement of Intracellular ROS Level}

Cell pellets of PAO1 from $500 \mu \mathrm{L}$ of overnight culture were harvested, and stained with $500 \mu \mathrm{L}$ of $20 \mu \mathrm{M} \mathrm{2} 2^{\prime}, 7^{\prime}$-dichlorofluorescein diacetate (carboxy- $\mathrm{H}_{2}$ DCFDA, dissolved in sterile PBS) at $37^{\circ} \mathrm{C}$ for $40 \mathrm{~min}$ under the dark condition. The treated cells were collected and washed with $500 \mu \mathrm{L}$ of sterile PBS three times to fully remove the carboxy- $\mathrm{H}_{2} \mathrm{DCFDA}$ that did not bind. The cells were resuspended in $500 \mu \mathrm{L}$ of PBS with or without $5 \mathrm{mM}$ sodium selenite and then incubate at $37^{\circ} \mathrm{C}$ in dark for $2 \mathrm{~h}$, and $4 \mathrm{mM} \mathrm{H}_{2} \mathrm{O}_{2}$ was used as a positive control. The cells were centrifuged, washed three times, and resuspended in PBS. A volume of $200 \mu \mathrm{L}$ of suspension was transferred into a black 96-well plate with transparent bottom and the fluorescence was measured using the microplate reader with emission at $528 \mathrm{~nm}$ and excitation at $485 \mathrm{~nm}$. The fluorescence data were normalized to the cell density of each sample. Three independent experiments were performed.

\subsection{Superoxide Dismutase (SOD) Activity Assay}

Overnight cultures were transferred at 1:100 into $10 \mathrm{~mL}$ of fresh LBNS liquid with or without $5 \mathrm{mM}$ and cultivated to an $\mathrm{OD}_{600}$ of 1.0. A volume of $2 \mathrm{~mL}$ of bacterial culture was harvested by centrifugation, washed twice, and finally resuspended in $1 \mathrm{~mL}$ of pre-cooling PBS. After Cells were lysed by ultrasonic crushing apparatus and centrifuged at $8000 \times g$ rpm for $5 \mathrm{~min}$, the supernatant was collected and the activity of SOD was measured using the SOD activity detection kit (Beyotime, Shanghai, China). The enzyme activity was normalized to the cell density of each sample. Three independently repeated experiments were carried out.

\subsection{RNA-Seq Sample Preparation and Sequencing}

The overnight culture was transferred to a fresh LBNS medium with or without $5 \mathrm{mM}$ sodium selenite and incubated to an $\mathrm{OD}_{600}=0.8$. The collected cells were washed once with PBS. The bacterial cell pellets were quickly frozen with liquid nitrogen before being sent to Hangzhou Lianchuan Biotechnology (Co. Ltd., Hangzhou, China) for total RNA extraction, cDNA library construction, and RNA-seq analysis. RNA-Seq was performed on the Illumina HiSeq ${ }^{\mathrm{TM}} 2000$ (San Diego, CA, USA). The raw paired-end reads were 
trimmed and quality controlled by Trimmomatic with parameters (version $0.36 \mathrm{http}: / /$ www.usadellab.org/cms/uploads/supplementary/Trimmomatic (accessed on 9 October 2020). Then clean reads were separately aligned to reference genome with orientation mode using Rockhopper (http:/ / cs.wellesley.edu/ btjaden/Rockhopper (accessed on 9 October 2020) software.

\subsection{Bioinformatics Analysis}

Differential expression genes (DEGs) of samples were detected using DESeq. The transcripts with $\log _{2}$ fold change $\geq 1$ and $P_{\text {adj }}(p$-value adjusted $) \leq 0.05$ were considered to be DEGs. The COG (Cluster of Orthologous Group) database of proteins was analyzed by BLAST, and the COG functional annotation was performed. Kyoto Encyclopedia of Genes and Genomes (KEGG) pathways enrichment was analyzed by using tools in the DAVID web server [29]. The number of DEGs in different KEGG pathways was counted to signaling pathways.

\subsection{Promoter Activity Assay}

The GFP reporter plasmid pHERD20T was used to construct transcriptional fusions with the promoters of the genes $p q s R$, las $R$, and $r h l R$. The promoter region was amplified by PCR. The DNA fragment was digested and cloned into the digested pHERD20 plasmid. The resulting plasmids were transferred into $P$. aeruginosa PAO1. The promoter activity was evaluated by measuring GFP intensity and $\mathrm{OD}_{600}$ in the microplate reader (Synergy H2, BioTek, Winooski, VT, USA).

\subsection{Chinese Cabbage Infection Assay}

A bacterial virulence test was performed as described previously with minor modifications [30]. P. aeruginosa PAO1 was grown in LBNS medium at $37^{\circ} \mathrm{C}$ overnight. After centrifugation, the bacterial cells were washed in $10 \mathrm{mM} \mathrm{MgSO}_{4}$ and diluted to $\mathrm{OD}_{600}=1.0$, and then $10 \mu \mathrm{L}$ of suspension was injected with a syringe into the midrib of Chinese cabbage leave after disinfection by $5 \%$ sodium hypochlorite and $70 \%$ ethanol. The leaves were placed on dishes containing a Whatman filter impregnated with $10 \mathrm{mM} \mathrm{MgSO}_{4}$. The plates were kept in an incubator at $37^{\circ} \mathrm{C}$, and rot symptoms were monitored every two days. Finally, the rotten part was cut off and soaked in $1 \mathrm{~mL}$ of PBS, and placed for $4{ }^{\circ} \mathrm{C}$ overnight. The cabbage was taken out and weighed, and the collected bacterial liquid was coated with a gradient dilution method to count the number of bacteria in the rotten part. The number of bacteria was expressed as $\mathrm{CFU} / \mathrm{mg}$. The experiments were repeated at least three times on independent periods.

\subsection{Drosophila Melanogaster Infection Assay}

P. aeruginosa PAO1 was grown overnight, washed, and diluted in $5 \%(w / v)$ sucrose to $\mathrm{OD}_{600}=2.0$. Groups of 10 male fruit-flies (five to seven days old) were starved for $3 \mathrm{~h}$ and then fed continuously at $25^{\circ} \mathrm{C}$ in vials with sterile filter papers, which had been previously added with the bacterial solution. Fruit-fly survival was monitored daily. Three groups of 30 fruit-flies were used for each condition in three independent experiments.

\subsection{Statistical Analysis}

All reported experiments were independently repeated at least three times. Statistical analysis was carried out using GraphPad Prism 5 and values mean \pm SD. The data were analyzed by one-way analysis of variance (ANOVA). A Student's $t$-test was used when one-way ANOVA revealed significant differences $(p<0.05)$. 


\section{Results}

3.1. Sodium Selenite Increased the Lethality Rate of P. aeruginosa PAO1 with Antibiotics or $\mathrm{H}_{2} \mathrm{O}_{2}$ Treatment and the Antibiotics Susceptibility in Planktonic and Biofilm States

The growth of $P$. aeruginosa PAO1 was firstly examined in the presence of sodium selenite in this study. As reported previously [20], sodium selenite showed antibacterial activity when the concentrations were more than $10 \mathrm{mM}$. When the concentration of sodium selenite was less than $5 \mathrm{mM}$, it had no significant effect on PAO1 growth in LBNS liquid (Figure S1). Therefore, sodium selenite of $5 \mathrm{mM}$ was selected for subsequent studies. Interestingly, the survival assay showed that $5 \mathrm{mM}$ sodium selenite obviously reduced the survival rate of PAO1 in the presence of antibiotics (Figure 1A-E), especially for the aminoglycoside antibiotic tobramycin (Figure 1B), the fluoroquinolone antibiotic ciprofloxacin (Figure 1D), and the $\beta$-lactam antibiotic ampicillin (Figure 1E). As regards the oxidant $\mathrm{H}_{2} \mathrm{O}_{2}$, when $5 \mathrm{mM}$ sodium selenite was combined to use, a similar result was obtained (Figure 1F). Taken together, the results showed that $5 \mathrm{mM}$ sodium selenite increased the lethality rate of P. aeruginosa in the presence of antibiotics and oxidant agents.

A

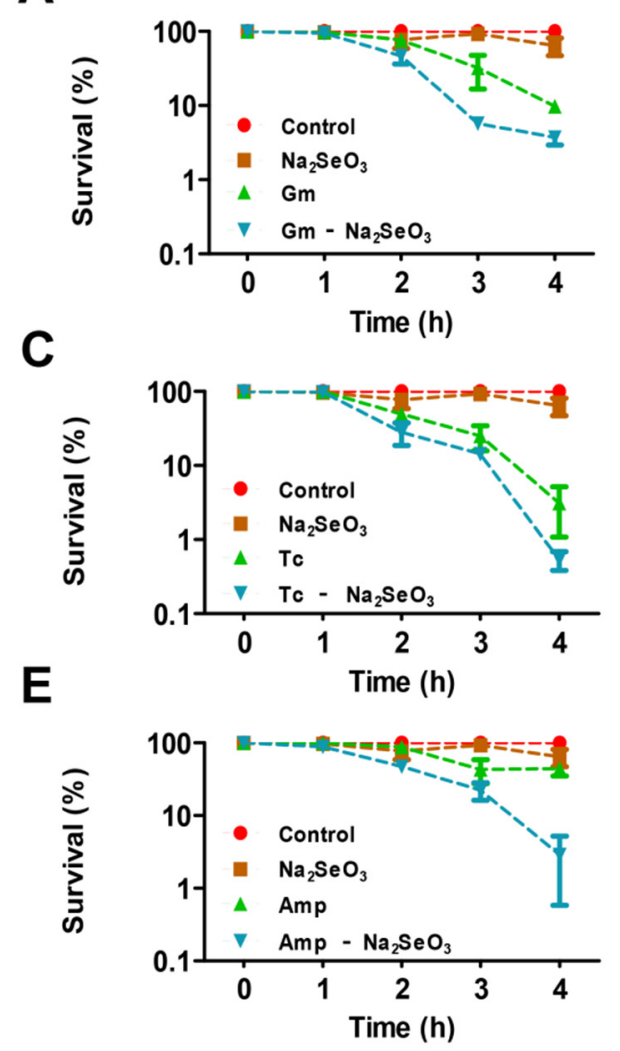

B
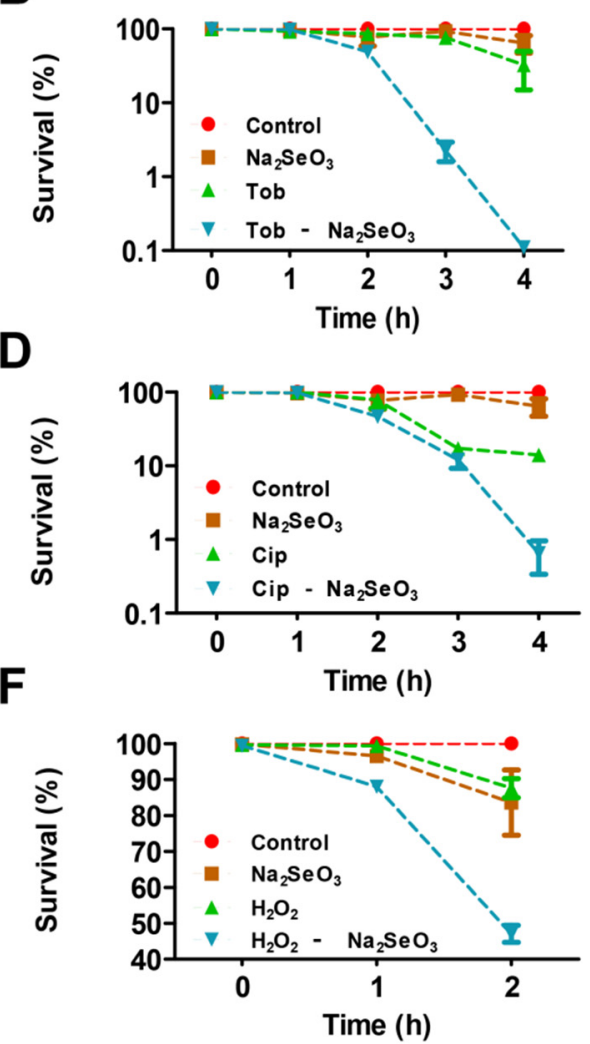

Figure 1. Evaluation of bacterial survival with antibiotics and sodium selenite treatment for various periods. (A) The survival rate of PAO1 treated with sodium selenite, gentamicin, or the combination of the two compounds. (B) The survival rate of PAO1 treated with sodium selenite, tobramycin, or the combination of the two compounds. (C) The survival rate of PAO1 treated with sodium selenite, tetracycline, and the combination of the two compounds. (D) The survival rate of PAO1 treated with sodium selenite, ciprofloxacin, or the combination of the two compounds. (E) The survival rate of PAO1 treated with sodium selenite, ampicillin, or the combination of the two compounds. (F) The survival rate of PAO1 treated with sodium selenite, $\mathrm{H}_{2} \mathrm{O}_{2}$, or a combination of the two compounds.

Furthermore, MIC values of antibiotics with or without sodium selenite were determined. When $5 \mathrm{mM}$ sodium selenite was used in combination with gentamicin or tobramycin, the MIC values of gentamicin or tobramycin were both remarkedly decreased (Figure 2A,B and Table S1), while $1 \mathrm{mM}$ sodium selenite had no obvious influence on 
the MIC values of these two antibiotics (Figure 2A,B). The results indicated that sodium selenite could enhance the antibiotic susceptibility of P. aeruginosa PAO1.
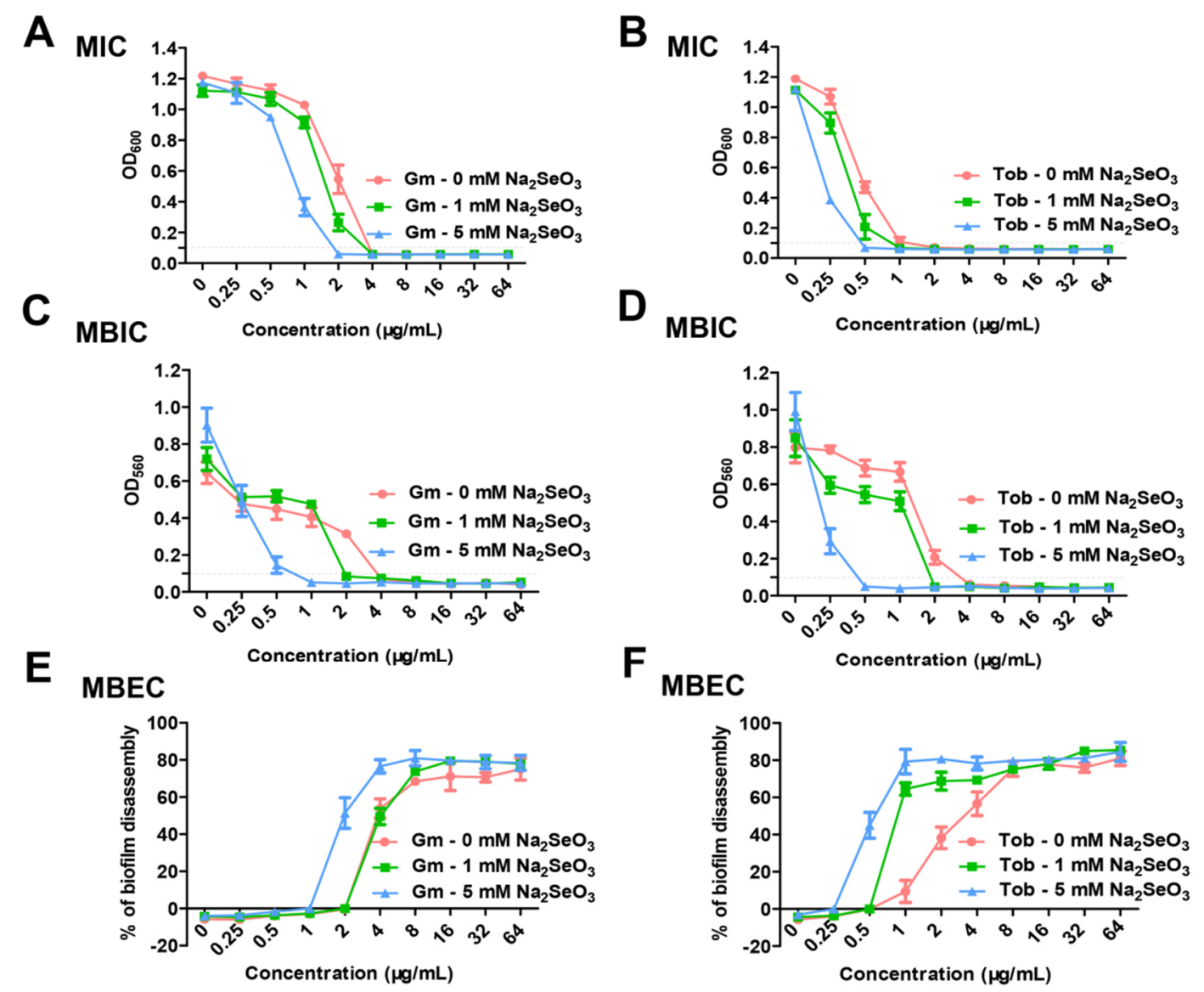

Figure 2. Effects of sodium selenite on the antibiotic susceptibility of PAO1. (A,B) PAO1 was treated with varying concentrations of gentamicin and tobramycin $(0.25$ to $64 \mu \mathrm{g} / \mathrm{mL})$ in LBNS broth at $37^{\circ} \mathrm{C}$ for $12 \mathrm{~h}$. The lowest concentration of antibiotics and sodium selenite that inhibited bacterial growth $\left(\mathrm{OD}_{600}<0.1\right)$ after $12 \mathrm{~h}$ incubation was taken as MIC. (C,D) PAO1 was treated with varying concentrations of gentamicin and tobramycin $(0.25$ to $64 \mu \mathrm{g} / \mathrm{mL})$ in LBNS broth and static growth at $30{ }^{\circ} \mathrm{C}$ for $12 \mathrm{~h}$. MBIC represents the minimum concentration of antibiotics and sodium selenite required to inhibit biofilm formation $\left(\mathrm{OD}_{560}<0.1\right)$. (E,F) The 10-h biofilm of PAO1 was treated with varying concentrations of gentamicin and tobramycin $(0.25$ to $64 \mu \mathrm{g} / \mathrm{mL})$ in LBNS broth and static growth at $30^{\circ} \mathrm{C}$ for $12 \mathrm{~h}$. All experiments were repeated independently three times.

It is known that biofilm formation increases the drug resistance of bacteria [31]. The effect of sodium selenite on the antibiotic susceptibility of $P$. aeruginosa in the biofilm state was further examined. The result showed that the MBIC value of gentamicin for 12-h static biofilm growth was $4 \mu \mathrm{g} / \mathrm{mL}$, whereas combined with $5 \mathrm{mM}$ sodium selenite, the MBIC value of gentamicin was reduced to $1 \mu \mathrm{g} / \mathrm{mL}$ (Figure 2C). The synergistic effect of sodium selenite with tobramycin also was observed, as the MBIC value of tobramycin was dramatically decreased from $4 \mu \mathrm{g} / \mathrm{mL}$ to $0.5 \mu \mathrm{g} / \mathrm{mL}$ (Figure 2D). In addition, the MBIC values of the two antibiotics were also obviously reduced in the presence of $1 \mathrm{mM}$ sodium selenite.

To determine whether sodium selenite enhanced the ability of antibiotics to eradicate the formed biofilm, we examined the MBEC values of gentamicin and tobramycin to eradicate a 10-h biofilm. As shown in Figure 2E,F, the MBEC values of gentamicin and tobramycin with sodium selenite were two-fold lower than those without sodium selenite. These results demonstrated that sodium selenite increased the antibiotic susceptibility 
of bacteria in the biofilm state, indicating that sodium selenite could be coupled with antibiotic therapy to combat biofilm-related infections.

3.2. Sodium Selenite Inhibited Biofilm Formation, Pyocyanin Production, Bacterial Motilities, and the Type III Secretion System (T3SS)

The effects of sodium selenite on the phenotypes related to the pathogenicity of $P$. aeruginosa were examined. The results showed that $5 \mathrm{mM}$ sodium selenite inhibited the formation of biofilms (Figure 3A). The production of pyocyanin was decreased from $3.15 \mu \mathrm{g} / \mathrm{mL}$ to $2.15 \mu \mathrm{g} / \mathrm{mL}$ in the presence of $5 \mathrm{mM}$ sodium selenite (Figure 3B). The motilities including swarming, swimming and twitching were all impaired by $5 \mathrm{mM}$ sodium selenite (Figure 3C). Furthermore, the swarming motility of PAO1 was totally inhibited (Figure S2). In addition, the rhamnolipid level was decreased when $5 \mathrm{mM}$ sodium selenite was added (Figure 3D). T3SS is the key virulence system relative to acute infection. The promoter activities of the T3SS effector genes exoT and exoS were analyzed using a lux -based reporter. As shown in Figure 3E,F, in the presence of $5 \mathrm{mM}$ sodium selenite, the expression of exoS and exoT was decreased significantly, indicating a decline of virulence. Taken together, these results suggested that $5 \mathrm{mM}$ sodium selenite could inhibit virulence factor production of $P$. aeruginosa PAO1.
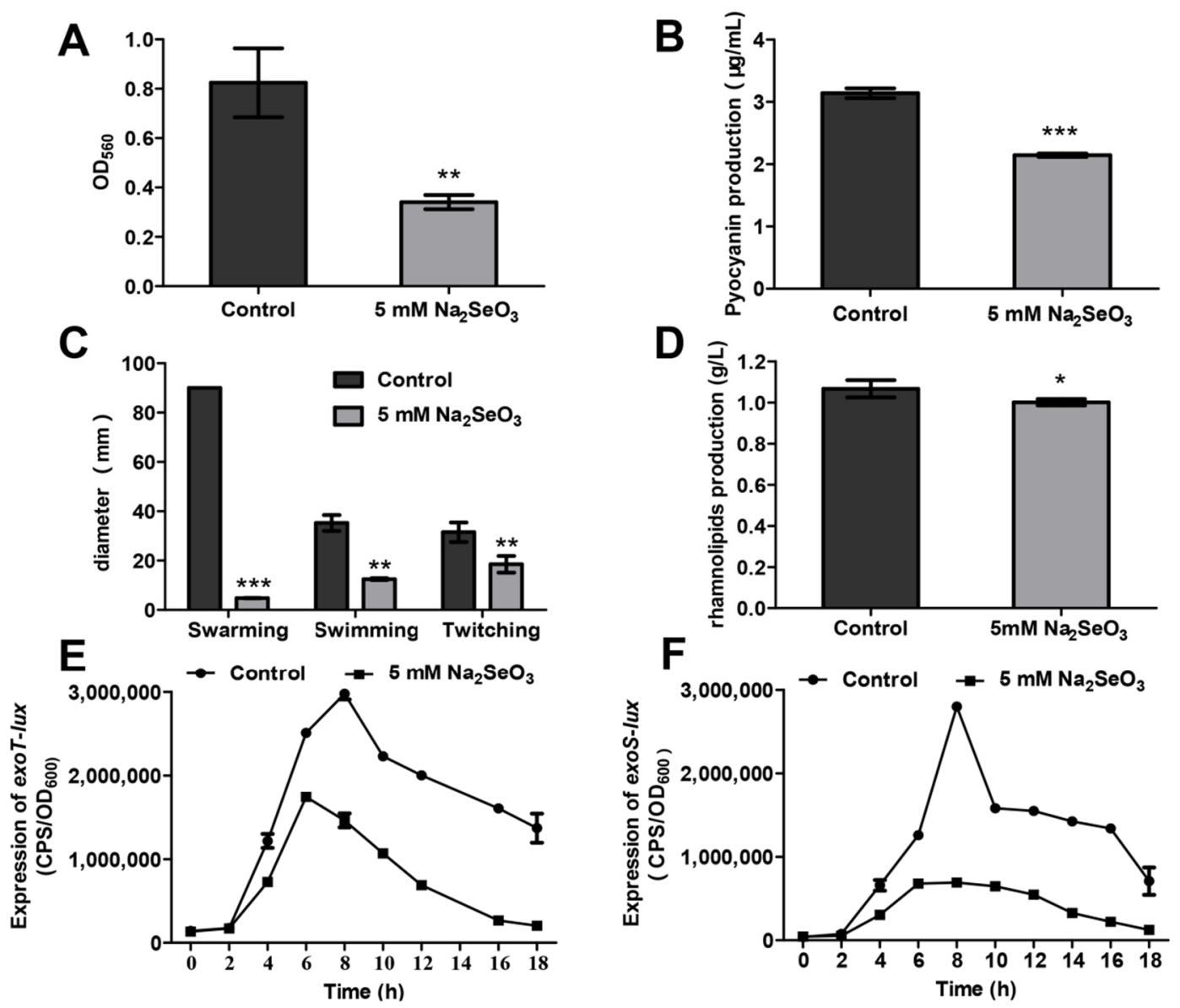

Figure 3. Sodium selenite affected biofilm formation (A), pyocyanin production (B), bacterial motilities (C), rhamnolipids production (D), and the expression of T3SS effector genes (E,F). For biofilm formation assay, the biomass of PAO1 was detected by CV staining after sodium selenite treatment. For the expression examination of T3SS effector genes, a CTX-exoT or CTX-exoS reporter fusion integrated on the chromosome was used to measure expression levels of T3SS genes under T3SS inducing conditions with or without sodium selenite after 18-h growth. All data were presented as mean \pm SD of three separate experiments. ${ }^{*} p<0.05,{ }^{* *} p<0.01,{ }^{* * *} p<0.001$, compared with the untreated control group. 


\subsection{RNA-Seq Analysis Revealed the Global Response of P. aeruginosa in the Presence of $5 \mathrm{mM}$} Sodium Selenite

To explore the global response of $P$. aeruginosa in the presence of $5 \mathrm{mM}$ sodium selenite, RNA-seq analysis was performed. A total of 1023 DEGs were detected, with 368 upregulated and 655 down-regulated (Figure $4 \mathrm{~A}$ ). Among them, the genes involved in the synthesis of pyocyanin, such as $p h z A 1, p h z A 2, p h z B 1$, and $p h z E 2$ were down-regulated, and the expression levels of the genes involved in bacterial motility, such as pilL, pilM, pilQ, pilO, pilG, pilH, and fliC were significantly reduced. These data were consistent with the results of the phenotypes mentioned above (Figure 3). The down-regulated genes were closely related to the virulence of $P$. aeruginosa, indicating that sodium selenite might affect its pathogenicity.

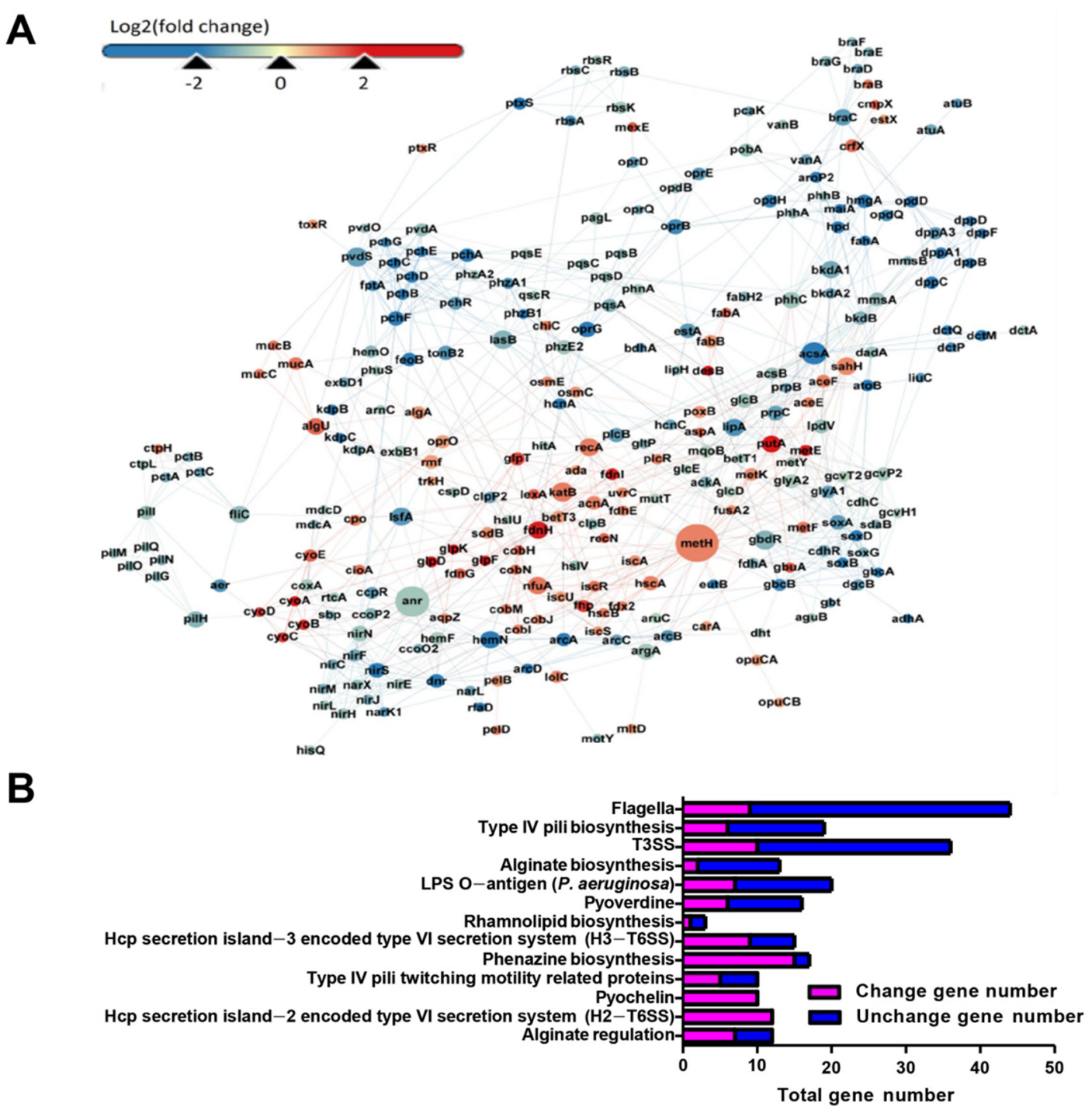

Figure 4. (A) Differential gene expression analysis diagram. Red represented high expression and blue represented low expression. The size of circles represented reliability, with bigger circles being higher reliability. (B) KEGG pathway analysis of DEGs. The top 13 classical pathways obtained through KEGG enrichment were shown.

Cluster analysis of COG was performed on all detected genes, and the results showed that the cluster of COG mainly was focused on amino acid transport and metabolism, energy production and conversion, inorganic ion transport and metabolism, lipid transport and metabolism, carbohydrates transport and metabolism, and signal transduction systems, and they accounted for $18.11 \%, 14.34 \%, 7.17 \%, 6.04 \%, 5.66 \%$, and $5.28 \%$, respectively (Figure S3). The results of cluster analysis of COG suggested that the presence of 
sodium selenite might inhibit the amino acid metabolism and carbohydrate metabolism, but improve the energy production of PAO1.

According to the results of the KEGG enrichment pathway, 13 significantly enriched pathways were selected. In each signal pathway, the total number of the genes and their expression changes were listed (Figure 4B). Among them, most DEGs were mainly enriched in the synthesis of pyocyanin and phenazines, type IV fimbria biosynthesis, flagella biosynthesis, alginate, and other extracellular polysaccharide synthesis pathways. In addition, a large number of DEGs were enriched in the type VI secretion system (T6SS) encoded by Hcp secretory Island-2 (H2-T6SS) and the Island-3 (H3-T6SS), two important virulence secretory systems of $P$. aeruginosa. In summary, the genes involved in the synthesis and secretion of various virulence factors were differentially expressed, indicating that sodium selenite had a significant effect on the virulence of $P$. aeruginosa.

\subsection{Sodium Selenite Inhibited the Expression of Quorum Sensing Genes}

RNA-seq results showed that many genes related to quorum sensing were differentially expressed (Table 2). The pqs system genes such as $p q s A B C D E$ were significantly inhibited. The genes related to $r h l$ system were also down-regulated. Previous studies have shown that $P$. aeruginosa activates the expression of many virulence genes by an intricate quorum sensing network. Therefore, in order to test whether sodium selenite inhibited virulence by affecting quorum sensing systems, the expression levels of $p q s R$, las $R$, and $r h l R$ were detected by the GFP reporter vectors. The result showed that the expression of these genes was decreased under the treatment of $5 \mathrm{mM}$ sodium selenite, especially for the expression of lasR and rhlR (Figure 5). These results suggested that sodium selenite might reduce the virulence production of PAO1 by inhibiting its quorum sensing systems.

Table 2. Differential expression genes involved in quorum sensing system.

\begin{tabular}{ccccc}
\hline Locus Tag & Gene Name & Fold Change & $\boldsymbol{P}_{\text {adj }}$ & Product \\
\hline PA0996 & $p q s A$ & 0.3252 & $1.01 \times 10^{-47}$ & PqsA \\
PA0997 & $p q s B$ & 0.3648 & $3.40 \times 10^{-38}$ & PqsB \\
PA0998 & $p q s C$ & 0.3866 & $6.23 \times 10^{-32}$ & PqsC \\
PA0999 & $p q s D$ & 0.3954 & $1.53 \times 10^{-33}$ & 3-oxoacyl-[acyl-carrier-protein] synthase III \\
PA1000 & $p q s E$ & 0.4951 & $3.45 \times 10^{-18}$ & quinolone signal response protein \\
PA1432 & lasI & 0.8302 & $9.27 \times 10^{-2}$ & autoinducer synthesis protein LasI \\
PA1430 & lasR & 0.9847 & $8.73 \times 10^{-3}$ & transcriptional regulator LasR \\
PA3476 & rhlI & 0.6924 & $2.36 \times 10^{-5}$ & autoinducer synthesis protein RhlI \\
PA3477 & rhlR & 0.7597 & $3.37 \times 10^{-4}$ & transcriptional regulator RhlR \\
\hline
\end{tabular}

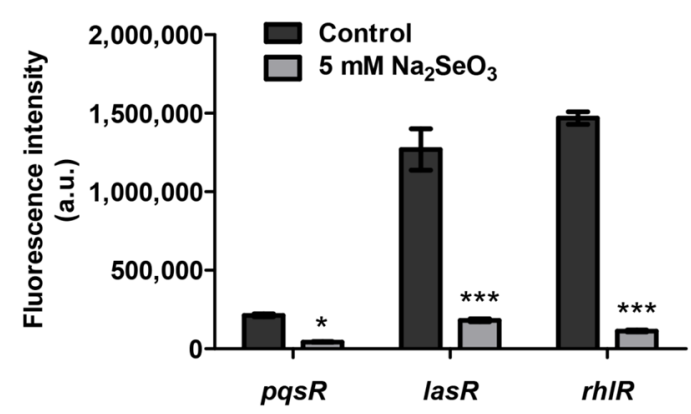

Figure 5. Sodium selenite inhibited the expression of quorum sensing genes $p q s R$, las $R$, and $r h l R$. The expression levels of $p q s R$, las $R$, and $r h l R$ were detected by the GFP reporter vectors. Arbitrary fluorescence units (a.u.) were defined by the GFP intensity normalized with $\mathrm{OD}_{600} \cdot{ }^{*} p<0.5$, *** $p<0.001$. 


\subsection{Sodium Selenite Increased the ROS Levels and the Expression of Oxidative Stress Related Genes}

Among DEGs, numerous oxidative stress related genes were observed in the presence of $5 \mathrm{mM}$ sodium selenite (Table 3), including $\operatorname{sodB}, k a t B, k a t E, \operatorname{ahpC}, \operatorname{ahpF}$, and $\operatorname{ahpB}$, which were regulated by two key regulation genes SoxR and OxyR. In addition, SoxR-regulated $z w f$ (coding 6-phospho-glucose dehydrogenase for NADPH formation) and acnA (coding aconitase for NADPH formation) were also highly expressed. The genes involved in glutathione synthesis, such as $g s h A$ and $g s h B$, were expressed at a low level. Taken together, the RNA-seq results confirmed that $5 \mathrm{mM}$ sodium selenite might induce oxidative stress. The generated oxidative damage not only enhanced the bacterial susceptibility to antibiotics and inhibited the virulence, but also increased the expression of antioxidant genes in $P$. aeruginosa for self-protection.

Table 3. Differential expression genes involved in oxidative stress.

\begin{tabular}{|c|c|c|c|c|}
\hline Locus Tag & Gene Name & Fold Change & $P_{\text {adj }}$ & Product \\
\hline PA2273 & $\operatorname{sox} R$ & 1.0377 & $7.98 \times 10^{-1}$ & SoxR \\
\hline PA3183 & $z w f$ & 1.1942 & $1.68 \times 10^{-2}$ & Glucose-6-phosphate 1-dehydrogenase \\
\hline PA4366 & $\operatorname{sodB}$ & 2.2508 & $7.69 \times 10^{-23}$ & superoxide dismutase \\
\hline PA1562 & $\operatorname{acn} A$ & 2.5174 & $1.32 \times 10^{-40}$ & aconitate hydratase 1 \\
\hline PA5344 & oxyR & 0.9082 & $2.24 \times 10^{-1}$ & OxyR \\
\hline PA4613 & katB & 2.6860 & $2.03 \times 10^{-39}$ & catalase \\
\hline PA2147 & katE & 1.9478 & $2.38 \times 10^{-4}$ & catalase HPII \\
\hline PA2185 & katN & 1.8293 & $3.23 \times 10^{-3}$ & non-heme catalase KatN \\
\hline PA0139 & $\operatorname{ahpC}$ & 1.1545 & $4.69 \times 10^{-2}$ & alkyl hydroperoxide reductase subunit $C$ \\
\hline PA0140 & $\operatorname{ahpF}$ & 1.6734 & $3.49 \times 10^{-13}$ & alkyl hydroperoxide reductase subunit $\mathrm{F}$ \\
\hline PA0848 & $\operatorname{ahpB}$ & 2.6370 & $2.96 \times 10^{-28}$ & alkyl hydroperoxide reductase \\
\hline PA2025 & gor & 1.3427 & $7.19 \times 10^{-5}$ & glutathione reductase \\
\hline PA5203 & $g \operatorname{sh} A$ & 0.8096 & $4.88 \times 10^{-3}$ & glutamate-cysteine ligase \\
\hline PA0407 & $g \operatorname{sh} B$ & 0.7360 & $6.81 \times 10^{-5}$ & glutathione synthetase \\
\hline PA4210 & phzA1 & 0.1995 & $1.20 \times 10^{-9}$ & probable phenazine biosynthesis protein \\
\hline PA1899 & phzA2 & 0.4405 & $1.28 \times 10^{-2}$ & probable phenazine biosynthesis protein \\
\hline PA4214 & phzE1 & 0.4272 & $1.17 \times 10^{-12}$ & phenazine biosynthesis protein PhzE \\
\hline PA1903 & phzE2 & 0.4272 & $1.17 \times 10^{-12}$ & phenazine biosynthesis protein PhzE \\
\hline PA3812 & $i s c A$ & 2.2484 & $1.52 \times 10^{-28}$ & probable iron-binding protein IscA \\
\hline PA3813 & iscu & 2.1258 & $4.92 \times 10^{-28}$ & probable iron-binding protein IscU \\
\hline PA4615 & $\operatorname{fpr} B$ & 2.8740 & $1.41 \times 10^{-46}$ & FprB \\
\hline PA2356 & $m s u D$ & 1.9334 & $2.24 \times 10^{-1}$ & methanesulfonate sulfonatase MsuD \\
\hline
\end{tabular}

It is reported that oxidative stress can affect the antibiotic susceptibility of pathogenic bacteria [32]. To investigate whether sodium selenite induced oxidative stress in P. aeruginosa, bacterial cells were labeled with a highly specific fluorescent probe, Carboxy-H2DCFDA, which is able to react with ROS and produce a fluorescent derivative $2^{\prime}, 7^{\prime}$-dichlorofluorescein (DCF) [33]. The result showed that the fluorescence intensity of cells treated with $5 \mathrm{mM}$ sodium selenite was two-fold higher compared with the untreated cells (Figure 6A), indicating that sodium selenite increased the ROS level of P. aeruginosa cells.

In general, bacterial cells adopt defense mechanisms to scavenge ROS under the oxidative stress conditions. To evaluate the response of P. aeruginosa, the expressions of genes involved in the antioxidant system include superoxide dismutase (SodM), catalase $(k a t B)$, alkyl hydroperoxidase $(a h p C)$, and glutathione synthetase $(g s h B)$ were examined. The results showed that the expression of most genes involved in oxidative stress was increased significantly in the presence of $5 \mathrm{mM}$ sodium selenite except $g s h B$ (Figure 6B). Since the expression of sodM was induced by sodium selenite, the SOD activity was further tested. The inhibition of $\mathrm{O}^{2-}$ and the SOD activity were both increased in the sodium selenite group (Figure $6 \mathrm{C}, \mathrm{D}$ ). Overall, these results demonstrated that sodium selenite 
stimulated the production of ROS in P. aeruginosa, which induced the increase of antioxidant enzyme activity to eliminate the toxicity of ROS.

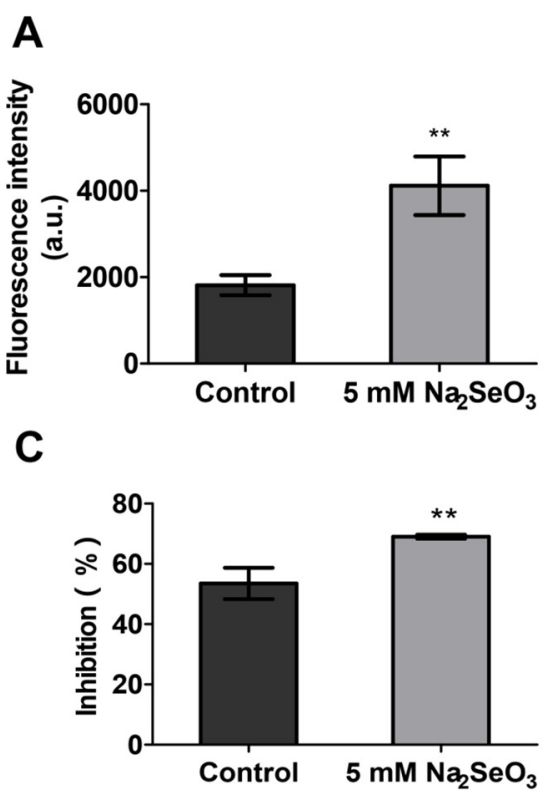

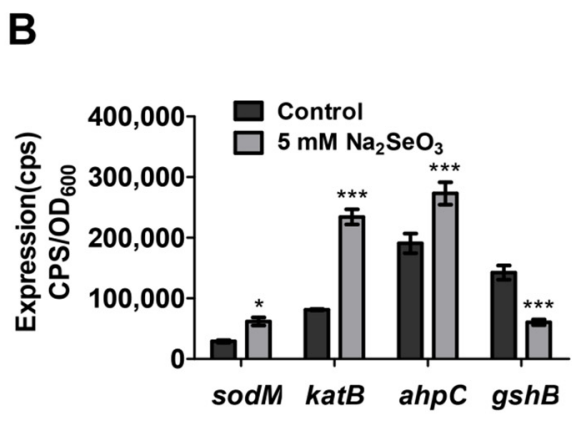

D

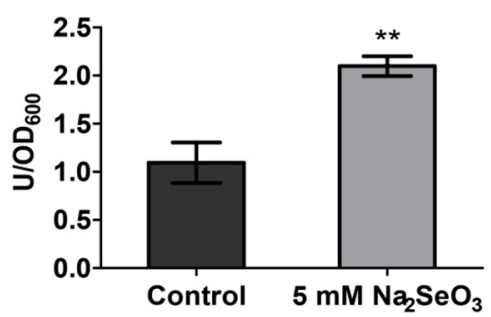

Figure 6. Sodium selenite induced oxidative stress. (A) Intracellular ROS levels were assessed by microplate reader using the probe Carboxy-H2DCFDA. (B) The expression levels of genes involved in oxidative stress were detected by using the reporter plasmid pMS402. (C) Measurement of the inhibition rate. It represented the hijacking of the $\mathrm{O}^{2-}$ and NBT reactions by SOD. (D) Measurement of total SOD activity. It was expressed as the enzyme activity unit $\mathrm{U} / \mathrm{OD}_{600}$. All data were presented as mean $\pm \mathrm{SD}$ of three separate experiments. ${ }^{*} p<0.5^{* * *} p<0.01,{ }^{* * *} p<0.001$.

3.6. Sodium Selenite Reduced the Virulence of P. aeruginosa in Chinese Cabbage and D. melanogaster Infection Models

The decrease of many virulence factors mentioned above indicated that the pathogenicity might be attenuated. Therefore, the damage of $P$. aeruginosa on Chinese cabbage leaves in the presence of sodium selenite was examined. The wild-type P. aeruginosa PAO1 strain inoculated into the middle rib of the Chinese cabbage was able to cause typical necrosis after inoculation for two days (Figure 7). When $5 \mathrm{mM}$ sodium selenite or sub-MIC tobramycin was added, the necrosis of Chinese cabbage was weakened. However, when they were combined, the cabbage necrosis was significantly reduced (Figure 7A). In addition, the enumeration of $P$. aeruginosa cells proved the remarkable alleviation of infection (Figure 7B).

Considering that sodium selenite induced oxidative stress can reduce the pathogenicity of PAO1 in vitro, the effect of sodium selenite was further evaluated in vivo model. We used a D. melanogaster infection model to detect the pathogenicity of PAO1. The results showed that the fruit-flies fed with P. aeruginosa PAO1 had a lower survival rate than those when $5 \mathrm{mM}$ sodium selenite or sub-MIC tobramycin was added, although the combination did not significantly increase survival (Figure S4). However, this result also reflected that $5 \mathrm{mM}$ sodium selenite showed no obvious toxicity to D. melanogaster. 


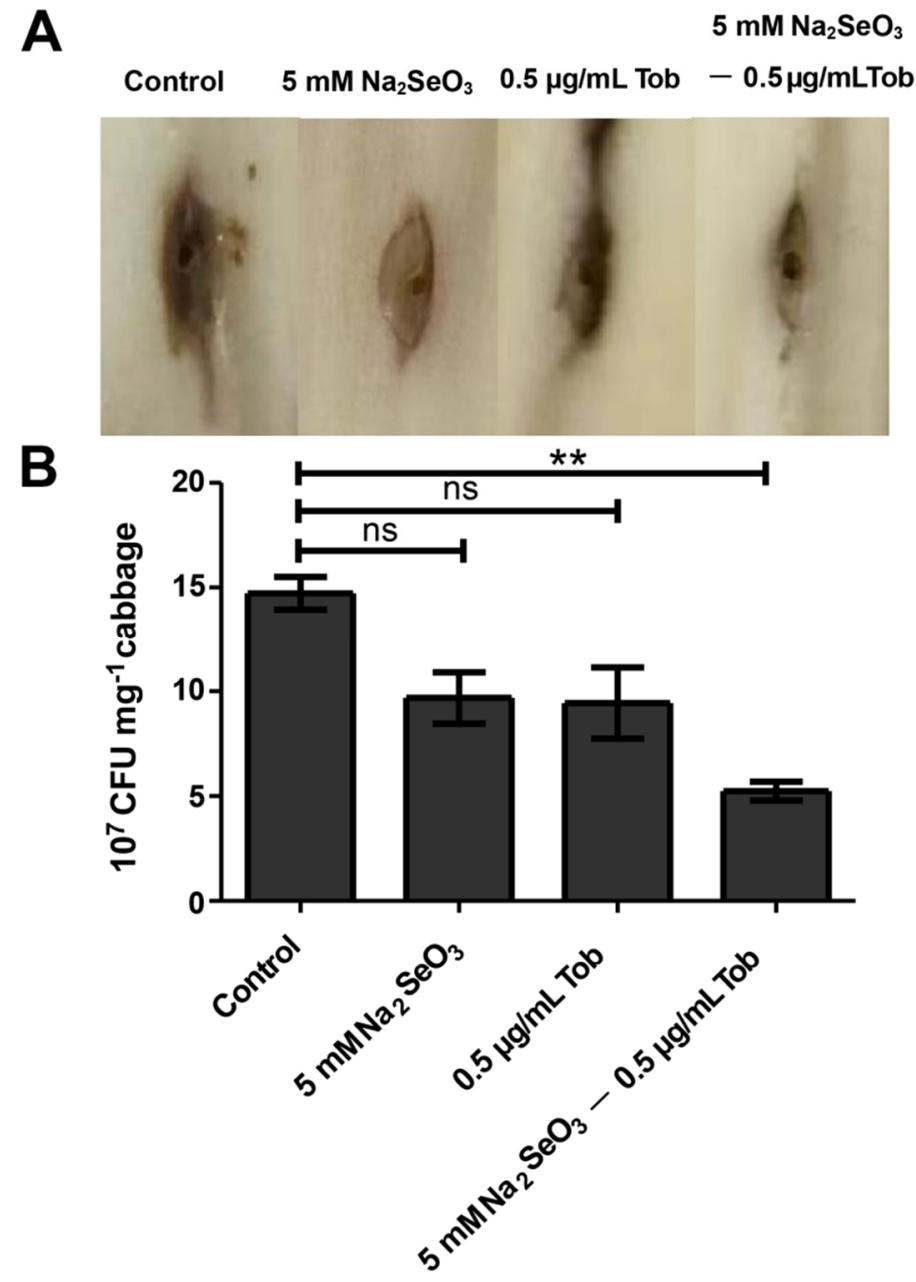

Figure 7. Sodium selenite in combination with tobramycin alleviated the virulence of PAO1. (A) The effects of $5 \mathrm{mM}$ sodium selenite after the infection with PAO1 for $24 \mathrm{~h}, 36 \mathrm{~h}$, and $48 \mathrm{~h}$. (B) The numbers of bacterial cells (indicated as CFU) presented in $1 \mathrm{mg}$ of cabbage midrib after injection for 2 days were shown. Error bars were calculated from three independent experiments, ${ }^{* *} p<0.01$, compared with the untreated control group; ns, no significance.

\section{Discussion}

The emergence and spread of drug-resistant bacteria have become a major public health problem [34]. P. aeruginosa is a persistent pathogen, and it evolves multiple antibiotic resistances, such as inhibition of enzymatic action and decreased uptake of antibiotics via target molecular mutation and efflux pump alternation [35]. Sodium selenite, a basic nutrient element of organisms, is a good choice for developing new antibacterial agents [36]. Therefore, in this study the potential antibacterial mechanisms of sodium selenite against P. aeruginosa were investigated.

We examined the effect of different concentrations of sodium selenite on P. aeruginosa PAO1 growth. The results showed that sodium selenite had no significant impact on the growth of PAO1 when the concentration was lower than $5 \mathrm{mM}$ (Figure S1). Therefore, sodium selenite of $5 \mathrm{mM}$ was selected for antibacterial activity investigation, which did not affect the growth of PAO1 and avoided the generation of resistant strains.

The survival rate after the treatment of sodium selenite and the MIC value was obviously reduced compared to the antibiotic application group (Figures 1 and 2). Further investigation demonstrated that the ROS level of the samples in the presence of sodium selenite was elevated and the bacterial anti-oxidant system was also induced (Figure 4), and therefore it was speculated that sodium selenite enhanced the antibiotics sensitivity of $P$. aeruginosa by inducing oxidative stress. Many antimicrobials exhibit bacteriological 
inactivation activity through ROS production [37], indicating that sodium selenite can be used as an adjunct drug of antibiotics to increase its killing effect and reduce the opportunity of drug-resistance bacterial occurrence.

Biofilm formation leads to strong resistance of bacteria to clinically common antibiotics and subsequently clinical refractory infection. Bacteria in the biofilm are reported to be 10 to 1000 times more resistant to antibiotics than the planktonic [38]. In this study, not only the biofilm formation was inhibited (Figure 2C,D), but also the eradication rate of the formed biofilm was increased when combined with antibiotics (Figure 2E,F). These results demonstrated that sodium selenite also increased the antibiotic susceptibility of bacteria in biofilm besides the planktonic, indicating a promising application potential of sodium selenite in biofilm inhibition and eradication.

The production of many virulence factors of P. aeruginosa PAO1 was inhibited by sodium selenite, including pyocyanin, rhamnolipid, and T3SS, and the motility of swarming, swimming, and twitching was all suppressed (Figure 3). These results might also lead to the decrease of bacterial antibiotics resistance in addition to pathogenicity. For example, pyocyanin, a virulence factor, is also involved in the biofilm formation and iron absorption of bacteria $[39,40]$. Rhamnolipid and motility are both related to bacterial biofilm formation [41,42].

Sodium selenite significantly inhibited the expression of quorum sensing related genes and significantly inhibited the virulence factors regulated by the quorum sensing. These results were validated by RNA-seq, indicating that sodium selenite might block quorum sensing system and reduce virulence factors production. These findings suggested that sodium selenite could be used as a quorum sensing inhibitor to reduce the virulence factor production and pathogenicity of $P$. aeruginosa. Quorum sensing inhibitors do not affect bacterial growth, but inhibit their virulence factors and reduce pathogenicity, while they do not cause bacterial drug resistance. Therefore, quorum sensing inhibitors are believed to generate weaker selection for antibiotic resistance than conventional antibiotics.

Sodium selenite promotes oxidative stress of P. aeruginosa. This bacterium has evolved various mechanisms to protect itself from oxidative stress and to survive in these adverse conditions. It is able to induce the antioxidant enzymes from the antioxidant system to balance ROS, such as SOD, catalase (CAT), and alkyl hydroperoxidase (AHPC), which catalyze the decomposition of $\mathrm{O}^{2-}, \mathrm{H}_{2} \mathrm{O}_{2}$, and $\mathrm{OH}^{-}$in bacterial cells, respectively, to resist the toxicity of ROS. In addition, this bacterium also produces a large number of antioxidant molecules, such as GSH. GSH, the first antioxidant in tissue defense, protects cells and tissues from oxidative damage by eliminating or blocking the production of ROS [43]. GSH is oxidized under oxidative stress, and the decrease of glutathione level is one of the general characteristics of oxidative stress [44]. Our data showed that the expression levels of these antioxidant enzyme genes $k a t B$, sodB, and $a h p C$ were increased while the expression level of $g s h B$ was decreased (Figure $6 \mathrm{~B}$ ). In addition, the activity of total SOD in PAO1 was increased under the treatment of sodium selenite (Figure 6C,D). Relevant studies have confirmed that when $P$. aeruginosa PAO1 was exposed to exogenous oxidative stress, the expression of antioxidant enzyme genes kat $B$ and $a h p C$ increased [45]. It is reported that after induction of $P$. aeruginosa by phytol isolated from aster yomena, ROS content in bacterial cells was increased, and the imbalance of the antioxidant defense system resulted in a decrease of glutathione GSH [46]. GSH also plays an important role in the oxidative stress, bacterial toxicity, and biofilm formation of $P$. aeruginosa [47]. It was confirmed that after $g s h B$ gene deletion mutation, the production of pyocyanin and pyoverdine decreased, and the cell swimming and twitching mobility decreased. These phenomena were consistent with our results. Taken together, these findings help to explain the antibacterial mechanism of sodium selenite.

The effect of sodium selenite on the pathogenicity of P. aeruginosa was tested by using a Chinese cabbage infection model (Figure 7). It is found that sodium selenite had a certain antibacterial effect, and alleviated the pathogenicity of P. aeruginosa. In addition, for the plant itself, sodium selenite may be a nutritional enhancer. Many studies have 
shown that foliar spray of sodium selenite can promote plant growth and improve plant nutrient [48]. Considering that sodium selenite reduced the toxicity of $P$. aeruginosa in Chinese cabbage infection, we hypothesized that this antibacterial activity of sodium selenite could also provide an advantage for animal immune defense. The results of the D. melanogaster infection model confirmed that sodium selenite had a certain inhibitory effect on the pathogenicity of PAO1, although the combination of antibiotics did not achieve a good antibacterial effect (Figure S4). This may be due to the fact that $D$. melanogaster itself metabolizes sodium selenite, and it is worthy to be explored in future work.

Currently, a new antimicrobial strategy is to target the key toxicity of pathogens, aiming to reduce the pathogenicity rather than the growth of microorganisms. The molecules that target virulence factors of pathogens are neither bacteriostatic nor bactericidal, and the probability of bacterial resistance development against these molecules is minimal due to less selection pressure [49]. Therefore, sodium selenite can be used as a potential alternative therapeutic agent or an adjunct therapy in combination with currently practiced antibiotic regimens to reduce disease progression and antibiotic use. However, it needs to be paid attention that although selenium is an essential nutrient element for the human body, inorganic sodium selenite has high toxicity [50], and its application in human antibacterial therapy still needs further exploration. Selenium nanoparticles (SeNPs) and organic selenium, such as selenium methionine, may be used for antibacterial treatment. SeNPs has the ability to destroy microbial biofilm formation [51,52] and has been used as an antibacterial agent, antioxidant and anticancer agent in medicine due to its good antibacterial and antioxidant properties, and has the potential to become a new therapeutic drug and selenium nutritional supplement $[53,54]$.

\section{Conclusions}

In this work we investigated the effects of sodium selenite on the antibiotic susceptibility and virulence related phenotype of $P$. aeruginosa PAO1. It was found that less than $5 \mathrm{mM}$ sodium selenite did not obviously affect the bacterial growth, but decreased the MIC, MBIC, and MBEC values of the antibiotics tested. Further investigation found that sodium selenite induced oxidative stress and increased ROS accumulation and antioxidant enzyme activity, which might be the reasons for antibiotic susceptibility changes. In addition, sodium selenite inhibited bacterial virulence and reduced pathogenicity by disturbing the expression of quorum sensing related genes. Taken together, the results demonstrated the influence of sodium selenite on the physiology of P. aeruginosa, and indicated a promising application potential of sodium selenite for $P$. aeruginosa infection, especially for the bacteria within biofilms.

Supplementary Materials: The following are available online at https:/ /www.mdpi.com/article/ 10.3390/antiox10121873/s1, Figure S1: Sodium selenite with the concentrations between 0.5-5 mM did not obviously affect the growth of P. aeruginosa PAO1, Figure S2: Sodium selenite inhibited the bacterial motilities, Figure S3: The COG enrichment analysis of the differentially expressed genes, Figure S4. Sodium selenite enhances the survival rate of Drosophila melanogaster, Table S1: The values of MIC, MBIC, and MBEC in the different combinations of antibiotics and sodium selenite

Author Contributions: S.W. and W.K. conceived and designed the project; S.W., W.K. and Q.T. wrote the paper; Q.T., Q.Y., Y.C., Y.L., G.W., L.W. and C.Z. acquired the data; Y.L., Q.T., G.W., S.X. and Y.S. analyzed and interpreted the data. All authors have read and agreed to the published version of the manuscript.

Funding: This study was supported by grants from the National Natural Science Foundation of China (31500111, 31770152, and 32170114) the Nature Science Foundation of Shaanxi Province (2020JM-424), and National Key R\&D Program of China (2021YFC1808902).

Institutional Review Board Statement: Not applicable.

Informed Consent Statement: Not applicable.

Data Availability Statement: All the data are available within the article or Supplementary Materials. 
Conflicts of Interest: The authors declare no conflict of interest.

\section{References}

1. Stover, C.K.; Pham, X.Q.; Erwin, A.L.; Mizoguchi, S.D.; Warrener, P.; Hickey, M.J.; Brinkman, F.S.; Hufnagle, W.O.; Kowalik, D.J.; Lagrou, M.; et al. Complete genome sequence of Pseudomonas aeruginosa PAO1, an opportunistic pathogen. Nature 2000, 406, 959-964. [CrossRef] [PubMed]

2. Grosso-Becerra, M.V.; Croda-García, G.; Merino, E.; Servín-González, L.; Mojica-Espinosa, R.; Soberón-Chávez, G. Regulation of Pseudomonas aeruginosa virulence factors by two novel RNA thermometers. Proc. Natl. Acad. Sci. USA 2014, 111, 15562-15567. [CrossRef] [PubMed]

3. Zhou, J.W.; Luo, H.Z.; Jiang, H.; Jian, T.K.; Chen, Z.Q.; Jia, A.Q. Hordenine: A novel quorum sensing inhibitor and antibiofilm agent against Pseudomonas aeruginosa. J. Agric. Food Chem. 2018, 66, 1620-1628. [CrossRef] [PubMed]

4. Chatterjee, M.; Anju, C.P.; Biswas, L.; Anil Kumar, V.; Gopi Mohan, C.; Biswas, R. Antibiotic resistance in Pseudomonas aeruginosa and alternative therapeutic options. Int. J. Med. Microbiol. 2016, 306, 48-58. [CrossRef]

5. Hurley, M.N.; Cámara, M.; Smyth, A.R. Novel approaches to the treatment of Pseudomonas aeruginosa infections in cystic fibrosis. Eur. Respir. J. 2012, 40, 1014-1023. [CrossRef]

6. Mukherjee, S.; Bassler, B.L. Bacterial quorum sensing in complex and dynamically changing environments. Nat. Rev. Microbiol. 2019, 17, 371-382. [CrossRef]

7. Engebrecht, J.; Nealson, K.; Silverman, M. Bacterial bioluminescence: Isolation and genetic analysis of functions from Vibrio fischeri. Cell 1983, 32, 773-781. [CrossRef]

8. Bronesky, D.; Wu, Z.; Marzi, S.; Walter, P.; Geissmann, T.; Moreau, K.; Vandenesch, F.; Caldelari, I.; Romby, P. Staphylococcus aureus RNAIII and its regulon link quorum sensing, stress responses, metabolic adaptation, and regulation of virulence gene expression. Annu. Rev. Microbiol. 2016, 70, 299-316. [CrossRef]

9. Barnard, A.M.; Bowden, S.D.; Burr, T.; Coulthurst, S.J.; Monson, R.E.; Salmond, G.P. Quorum sensing, virulence and secondary metabolite production in plant soft-rotting bacteria. Philos. Trans. R. Soc. London. Ser. B Biol. Sci. 2007, 362, 1165-1183. [CrossRef]

10. Hammer, B.K.; Bassler, B.L. Quorum sensing controls biofilm formation in Vibrio cholerae. Mol. Microbiol. 2003, 50, 101-104. [CrossRef]

11. García-Contreras, R. Is quorum sensing interference a viable alternative to treat pseudomonas aeruginosa infections? Front. Microbiol. 2016, 7, 1454. [CrossRef] [PubMed]

12. Schwarz, K.; Foltzs, C.M. Selenium as an integral part of factor 3 against dietary necrotic liver degeneration. Nutrition 1999, 15, 225.

13. Biswas, K.C.; Barton, L.L.; Tsui, W.L.; Shuman, K.; Eze, C.S. A novel method for the measurement of elemental selenium produced by bacterial reduction of selenite. J. Microbiol. Meth. 2011, 86, 140-144. [CrossRef] [PubMed]

14. Li, D.B.; Cheng, Y.Y.; Wu, C.; Li, W.W.; Li, N.; Yang, Z.C.; Tong, Z.H.; Yu, H.Q. Selenite reduction by Shewanella oneidensis MR-1 is mediated by fumarate reductase in periplasm. Sci. Rep. 2014, 4, 3735. [CrossRef] [PubMed]

15. Spallholz, J.E. On the nature of selenium toxicity and carcinostatic activity. Free Radic. Biol. Med. 1994, 17, 45-64. [CrossRef]

16. Cihalova, K.; Chudobova, D.; Michalek, P.; Moulick, A.; Guran, R.; Kopel, P.; Adam, V.; Kizek, R. Staphylococcus aureus and MRSA growth and biofilm formation after treatment with antibiotics and SeNPs. Int. J. Mol. Sci. 2015, 16, 24656-24672. [CrossRef]

17. Misra, S.; Boylan, M.; Selvam, A.; Spallholz, J.E.; Björnstedt, M. Redox-active selenium compounds-From toxicity and cell death to cancer treatment. Nutrients 2015, 7, 3536-3556. [CrossRef]

18. Fernandes, A.P.; Gandin, V. Selenium compounds as therapeutic agents in cancer. Biochim. Biophys. Acta 2015, 1850, 1642-1660. [CrossRef]

19. Hatfield, D.L. Redox pioneer: Professor Vadim N. gladyshev. Antioxid. Redox Signal. 2016, 25, 1-9. [CrossRef]

20. Firoz, A.M.; Safhi, M.M.; Sivagurunathan, M.S.; Aamena, J. In vitro antibacterial spectrum of sodium selenite against selected human pathogenic bacterial strains. Scientifica 2016, 2016, 9176273. [CrossRef]

21. Wang, S.; Yu, S.; Zhang, Z.; Wei, Q.; Yan, L.; Ai, G.; Liu, H.; Ma, L.Z. Coordination of swarming motility, biosurfactant synthesis, and biofilm matrix exopolysaccharide production in Pseudomonas aeruginosa. Appl. Environ. Microbiol. 2014, 80, 6724-6732. [CrossRef] [PubMed]

22. Brynildsen, M.P.; Winkler, J.A.; Spina, C.S.; MacDonald, I.C.; Collins, J.J. Potentiating antibacterial activity by predictably enhancing endogenous microbial ROS production. Nat. Biotechnol. 2013, 31, 160-165. [CrossRef] [PubMed]

23. Cockerill, F.R.; Wiker, M.A.; Alder, J.; Dudley, M.N.; Eliopoulos, G.M.; Ferraro, M.J.; Hardy, D.J.; Hecht, D.W.; Hindler, J.A.; Patel, J.B. Methods for Dilution Antimicrobial Susceptibility Tests for Bacteria that Grow Aerobically, 9th ed.; CLSI: Wayne, PA, USA, 2012.

24. Ma, L.; Jackson, K.D.; Landry, R.M.; Parsek, M.R.; Wozniak, D.J. Analysis of Pseudomonas aeruginosa conditional psl variants reveals roles for the psl polysaccharide in adhesion and maintaining biofilm structure postattachment. J. Bacteriol. 2006, 188, 8213-8221. [CrossRef] [PubMed]

25. Leoni, L.; Rampioni, G. A coculture-based approach for screening campaigns aimed at identifying novel Pseudomonas aeruginosa quorum sensing inhibitors. Methods Mol. Biol. 2018, 1673, 287-296.

26. Kurachi, M. Studies on the biosynthesis of pyocyanine. (II): Isolation and determination of pyocyanine. Bull. Inst. Chem. Res. Kyoto Univ. 1958, 36, 174-187. 
27. Chayabutra, C.; Wu, J.; Ju, L.K. Rhamnolipid production by Pseudomonas aeruginosa under denitrification: Effects of limiting nutrients and carbon substrates. Biotechnol. Bioeng. 2001, 72, 25-33. [CrossRef]

28. Duan, K.; Dammel, C.; Stein, J.; Rabin, H.; MG, S. Modulation of Pseudomonas aeruginosa gene expression by host microflora through interspecies communication. Mol. Microbiol. 2003, 50, 1477-1491. [CrossRef]

29. Dennis, G., Jr.; Sherman, B.T.; Hosack, D.A.; Yang, J.; Gao, W.; Lane, H.C.; Lempicki, R.A. DAVID: Database for annotation, visualization, and integrated discovery. Genome Biol. 2003, 4, P3. [CrossRef]

30. Fito-Boncompte, L.; Chapalain, A.; Bouffartigues, E.; Chaker, H.; Lesouhaitier, O.; Gicquel, G.; Bazire, A.; Madi, A.; Connil, N.; Veron, W.; et al. Full virulence of Pseudomonas aeruginosa requires OprF. Infect. Immun. 2011, 79, 1176-1186. [CrossRef]

31. Wang, S.; Liu, X.; Liu, H.; Zhang, L.; Guo, Y.; Yu, S.; Wozniak, D.J.; Ma, L.Z. The exopolysaccharide Psl-eDNA interaction enables the formation of a biofilm skeleton in Pseudomonas aeruginosa. Environ. Microbiol. Rep. 2015, 7, 330-340. [CrossRef]

32. Schieber, M.; Chandel, N.S. ROS function in redox signaling and oxidative stress. Curr. Biol. 2014, 24, R453-R462. [CrossRef] [PubMed]

33. Rastogi, R.P.; Singh, S.P.; Häder, D.P.; Sinha, R.P. Detection of reactive oxygen species (ROS) by the oxidant-sensing probe $2^{\prime}, 7^{\prime}$-dichlorodihydrofluorescein diacetate in the cyanobacterium Anabaena variabilis PCC 7937. Biochem. Biophys. Res. Commun. 2010, 397, 603-607. [CrossRef] [PubMed]

34. Ventola, C.L. The antibiotic resistance crisis: Part 1: Causes and threats. Pharm. Ther. 2015, 40, $277-283$.

35. Jayaraman, P.; Sakharkar, M.K.; Lim, C.S.; Tang, T.H.; Sakharkar, K.R. Activity and interactions of antibiotic and phytochemical combinations against Pseudomonas aeruginosa in vitro. Int. J. Biol. Sci. 2010, 6, 556-568. [CrossRef] [PubMed]

36. Tran, P.A.; Webster, T.J. Selenium nanoparticles inhibit Staphylococcus aureus growth. Int. J. Nanomed. 2011, 6, 1553-1558. [CrossRef]

37. Moradali, M.F.; Ghods, S.; Rehm, B.H. Pseudomonas aeruginosa lifestyle: A paradigm for adaptation, survival, and persistence. Front. Cell. Infect. Microbiol. 2017, 7, 39. [CrossRef]

38. Xu, Z.; Fang, X.; Wood, T.K.; Huang, Z.J. A systems-level approach for investigating Pseudomonas aeruginosa biofilm formation. PLoS ONE 2013, 8, e57050. [CrossRef]

39. Das, T.; Manefield, M. Pyocyanin promotes extracellular DNA release in Pseudomonas aeruginosa. PLoS ONE 2012, 7, e46718. [CrossRef]

40. Kaufmann, G.F.; Sartorio, R.; Lee, S.H.; Rogers, C.J.; Meijler, M.M.; Moss, J.A.; Clapham, B.; Brogan, A.P.; Dickerson, T.J.; Janda, K.D. Revisiting quorum sensing: Discovery of additional chemical and biological functions for 3-oxo-N-acylhomoserine lactones. Proc. Natl. Acad. Sci. USA 2005, 102, 309-314. [CrossRef]

41. Nickzad, A.; Déziel, E. The involvement of rhamnolipids in microbial cell adhesion and biofilm development-An approach for control? Lett. Appl. Microbiol. 2014, 58, 447-453. [CrossRef]

42. Conrad, J.C. Physics of bacterial near-surface motility using flagella and type IV pili: Implications for biofilm formation. Res. Microbiol. 2012, 163, 619-629. [CrossRef] [PubMed]

43. Jamieson, D.J. Oxidative stress responses of the yeast Saccharomyces cerevisiae. Yeast 1998, 14, 1511-1527. [CrossRef]

44. Smirnova, G.V.; Oktyabrsky, O.N. Glutathione in bacteria. Biochemistry 2005, 70, 1199-1211. [CrossRef] [PubMed]

45. Ochsner, U.A.; Vasil, M.L.; Alsabbagh, E.; Parvatiyar, K.; Hassett, D.J. Role of the Pseudomonas aeruginosa oxyR-recG operon in oxidative stress defense and DNA repair: OxyR-dependent regulation of katB-ankB, ahpB and ahpC-ahpF. J. Bacteriol. 2000, 182, 4533-4544. [CrossRef]

46. Lee, W.; Woo, E.R.; Lee, D.G. Phytol has antibacterial property by inducing oxidative stress response in Pseudomonas aeruginosa. Free Radic. Res. 2016, 50, 1309-1318. [CrossRef]

47. Wongsaroj, L.; Saninjuk, K.; Romsang, A.; Duang-Nkern, J.; Trinachartvanit, W.; Vattanaviboon, P.; Mongkolsuk, S. Pseudomonas aeruginosa glutathione biosynthesis genes play multiple roles in stress protection, bacterial virulence and biofilm formation. PLoS ONE 2018, 13, e0205815. [CrossRef]

48. Fang, Y.; Zhang, Y.; Catron, B.; Chan, Q.; Hu, Q.; Caruso, J.A. Identification of selenium compounds using HPLC-ICPMS and nano-ESI-MS in selenium-enriched rice via foliar application. J. Anal. At. Spectrom. 2009, 24, 1657-1664. [CrossRef]

49. Cegelski, L.; Marshall, G.R.; Eldridge, G.R.; Hultgren, S.J. The biology and future prospects of antivirulence therapies. Nat. Rev. Microbiol. 2008, 6, 17-27. [CrossRef]

50. Benko, I.; Nagy, G.; Tanczos, B.; Ungvari, E.; Sztrik, A.; Eszenyi, P.; Prokisch, J.; Banfalvi, G. Subacute toxicity of nano-selenium compared to other selenium species in mice. Environ. Toxicol. Chem. 2012, 31, 2812-2820. [CrossRef]

51. Zonaro, E.; Lampis, S.; Turner, R.J.; Qazi, S.J.; Vallini, G. Biogenic selenium and tellurium nanoparticles synthesized by environmental microbial isolates efficaciously inhibit bacterial planktonic cultures and biofilms. Front. Microbiol. 2015, 6, 584. [CrossRef]

52. Wang, L.; Hu, C.; Shao, L. The antimicrobial activity of nanoparticles: Present situation and prospects for the future. Int. J. Nanomed. 2017, 12, 1227-1249. [CrossRef] [PubMed]

53. Yazdi, M.H.; Mahdavi, M.; Varastehmoradi, B.; Faramarzi, M.A.; Shahverdi, A.R. The immunostimulatory effect of biogenic selenium nanoparticles on the $4 \mathrm{~T} 1$ breast cancer model: An in vivo study. Biol. Trace Elem. Res. 2012, 149, 22-28. [CrossRef] [PubMed]

54. Forootanfar, H.; Adeli-Sardou, M.; Nikkhoo, M.; Mehrabani, M.; Amir-Heidari, B.; Shahverdi, A.R.; Shakibaie, M. Antioxidant and cytotoxic effect of biologically synthesized selenium nanoparticles in comparison to selenium dioxide. J. Trace Elem. Med. Biol. 2014, 28, 75-79. [CrossRef] [PubMed] 